\title{
Lexical activation during the recognition of Chinese characters: Evidence against early phonological activation
}

\author{
HSUAN-CHIH CHEN \\ Chinese University of Hong Kong, Hong Kong \\ and \\ HUA SHU \\ Beijing Normal University, Beijing, China
}

\begin{abstract}
In two primed-naming experiments involving Chinese character recognition, one with native Mandarinspeaking subjects and another with native Cantonese-speaking subjects, we varied both the stimulus onset asynchrony (SOA) and the prime-target similarity along various lexical dimensions. Across both experiments, the results were as follows: (1) Relatively strong and reliable semantic priming appeared very early across various SOAs, and its onset was not affected by meaning precision, (2) either homophonic priming had negligible effects on target naming or the effects appeared relatively late (only at $57 \mathrm{msec}$ ), and (3) graphic inhibition was found across different SOAs. Since the same set of stimuli and procedure were adopted as those in the study of Perfetti and Tan (1998), the present findings raise questions about the reliability and validity of the results from their study that have been used to support the notion that phonology is a constitutive element of character recognition and precedes meaning access in the identification process. Instead, the present results suggest that phonology is optional for accessing meaning in Chinese character recognition among skilled adult readers.
\end{abstract}

The question with which the present study is concerned is the process of recognizing characters in a rather unique written language, Chinese, which differs in important ways from European languages (Chen, 1992, 1996). For instance, most European languages adopt an alphabetic writing system in which the graphic symbols are made to correspond more or less to basic units in speech-that is, phonemes. Written Chinese, however, has been developed according to a logographic principle (i.e., one in which symbols mainly and directly encode meaning). In fact, Chinese characters generally represent lexical morphemes. Because various orthographies are constructed on distinct principles and present linguistic information in diverse forms, it is by no means self-evident that the same processes are activated to recognize information written in the different orthographies. Hence, it is important and useful to carry out word recognition research across orthographies, because it has the potential to reveal both universal and orthography-specific processes involved in the

This research was supported by Earmarked Grants from the Research Grants Council of Hong Kong, a Direct Grant for Research from the Social Science and Education Panel of the Chinese University of Hong Kong, and a departmental grant to H.-C.C. We are grateful to Sum-Yin Wong, Ming Lai, Iris Wong, Yanchao Bi, and Xiaolin Zhou for their assistance during various phases of these experiments. Correspondence concerning this article should be addressed to H.-C. Chen, Department of Psychology, The Chinese University of Hong Kong, Shatin, N.T., Hong Kong (e-mail: hcchen@psy.cuhk.edu.hk). recognition of words, which, in turn, can help to build a comprehensive theory of visual word recognition.

Recently, Perfetti and Tan (1998) reported a study in which the process of Chinese character recognition was investigated. In two primed-naming experiments by varying prime type (graphically similar, homophonic, semantically similar, or unrelated) and prime-target stimulus onset asynchrony (SOA; i.e., $115 \mathrm{msec}$ in Experiment 1 and 43, 57, and $85 \mathrm{msec}$ in Experiment 2), they found that (1) the pattern of priming induced from graphically similar primes shifted from facilitation at a $43-\mathrm{msec}$ SOA to inhibition at longer SOAs and disappeared at $115 \mathrm{msec}$, (2) homophonic primes facilitated target naming at 57msec and other longer SOAs, and (3) semantically similar primes with precise meanings started to produce facilitatory effects at an 85-msec SOA, whereas semantic primes with vague meanings revealed facilitation only at a 115msec SOA. The most critical finding was that phonological priming occurs at much shorter SOAs than does semantic priming. In fact, their results were interpreted as evidence that lexical activation in Chinese character recognition follows the sequence of graphic, phonological, and semantic and that the onset of semantic priming is a function of the precision of meaning of the prime item. These observations, if valid, have important implications, because sublexical phonology that is available in an alphabetic language is simply impossible in logographic Chinese. Thus, if it were indeed the case that phonological priming did occur earlier than semantic priming in Chinese, 
it would be considered to be in line with accounts of reading that propose that phonology plays a crucial role in visual word recognition across orthographies.

There are, however, some points in Perfetti and Tan's (1998) study that deserve attention. For instance, two aspects of Perfetti and Tan's findings seem rather unusual when compared with those in other studies adopting a similar primed-naming task. First, the magnitude of their priming effects in naming was much larger than those obtained in other studies of both Chinese (e.g., Experiment 4 of Perfetti \& Zhang, 1991; Shen \& Forster, 1999; Zhou \& Marslen-Wilson, 1997) and English (e.g., Forster \& Davis, 1991; Lukatela \& Turvey, 1994; Perea \& Gotor, 1997). In fact, the magnitude of priming in other studies hardly goes beyond $50 \mathrm{msec}$, whereas most of the priming effects in Perfetti and Tan's study were close to or even larger than $100 \mathrm{msec}$. Second, a number of recent investigations on visual word recognition have shown that reliable semantic-priming effects could be found at very short SOAs, such as $57 \mathrm{msec}$ (Zhou \& Marslen-Wilson, 1997) and $67 \mathrm{msec}$ (Perea \& Gotor, 1997), whereas similar effects only appeared at an $85 \mathrm{msec}$ SOA in the study of Perfetti and Tan.

Moreover, although Perfetti and Tan's (1998) naming latency data are very clear and are consistent with the interpretations they provided, their error data do not converge with their naming latency results. For example, as was mentioned above, their naming latency data in Experiment 2 revealed that homophonic primes produced faster and stronger priming than did semantically similar primes. However, their error data in the same experiment showed the completely opposite pattern (i.e., semantic primes produced fewer errors than homophonic primes across different SOAs, regardless of whether the primes had semantically vague or precise meanings). In other words, in contrast to the conclusion based on their naming latency data, their error data actually suggest that semantic, rather than phonological, activation plays a more crucial role in Chinese character recognition.

Finally, since Chinese characters are logographicin nature (i.e., characters basically represent morphemes) and the Chinese language has a high degree of homophony ${ }^{1}$ and a highly opaque symbol-to-sound correspondence, ${ }^{2}$ it is not clear whether the same kind of phonological activation that has been observed in word recognition with alphabetic systems (e.g., prelexical phonology) will also underlie character recognition in Chinese. Indeed, the role of phonology in the recognition and memory of Chinese characters has been a controversial issue in the literature. For instance, some researchers (e.g., Perfetti \& Tan, 1998; Perfetti \& Zhang, 1991, 1995; Tan, Hoosain, \& Siok, 1996; Tan \& Perfetti, 1997) claim that the phonological representation of a character is automatically and rapidly activated when the character is recognized and that such activation plays a crucial role for accessing the meaning of the character. Others (e.g., Chen, Flores d'Arcais, \& Cheung, 1995; Chen \& Juola, 1982; Shen \& Forster, 1999; Wong \& Chen, 1999), however, maintain that phonological information plays a much less important role in the recognition and memory of Chinese characters than does orthographic or semantic information. Before one can start to evaluate the psychological reality of these alternative positions, it is essential to see whether the main results of previous studies on the topic can be replicated, especially because some of the mentioned findings (e.g., Perfetti \& Zhang, 1991; Tan \& Perfetti, 1997) have proven difficult to replicate (e.g., Chen, Flores d'Arcais, \& Cheung, 1994; Zhou \& Marslen-Wilson, 1999).

Because of the arguments mentioned above, and also because strong theoretical claims have been based on the results of Perfetti and Tan (1998), it was decided to test whether the main results of the Perfetti and Tan study would be found when their stimuli and procedure were repeated in other laboratories. Since (1) the key findings of Perfetti and Tan were obtained mainly from the second experiment of their study and (2) this experiment had a wider range of SOA manipulation (from 43 to $85 \mathrm{msec}$ ) than did the first one (in which only a relatively long SOA [i.e., $115 \mathrm{msec}$ ], was adopted), only Experiment 2 of the original study was targeted for replication.

\section{EXPERIMENT 1 The Beijing Study}

\section{Method}

Subjects. Sixty native Mandarin-speaking undergraduates, recruited from the Beijing Normal University, participated in this experiment. All reported normal or corrected-to-normal vision.

Apparatus. All the stimuli were presented on a SOCOS color monitor. The experiment was controlled by a Pentium PC using the DMASTR software developed by K. I. Forster and J. C. Forster at the University of Arizona. Because the manipulation of SOAs is crucial in the experiment, we used a Panasonic AG-7750 video cassette recorder to verify whether the DMASTR software can indeed produce the desired timing value. This was done at the Chinese University of Hong Kong by using the video recorder to film the display of a character for a fixed duration. We then counted the number of frames in the resulting record, using a video analyzer to calculate how long the character was actually displayed on the computer monitor. It turned out that the actual display of a 1,000-msec presentation was $994.4 \mathrm{msec}$ (i.e., the difference was only $5.6 \mathrm{msec}$ ), indicating that the software is capable of generating highly accurate timing values.

The stimuli were presented in the center of the screen in white 24-point Kai-Ti font against a black background. Each character was approximately $1.2 \mathrm{~cm}$ in height and $1.0 \mathrm{~cm}$ in width. The luminance of the display screen was fixed at the same comfortable level for all the subjects (e.g., the luminance of the character 顛 was $13.0 \mathrm{~cd} / \mathrm{m}^{2}$ ). The subjects were seated approximately $50 \mathrm{~cm}$ from the display monitor. To reduce glare on the screen, the experiment was conducted in a semidarkened room.

Materials and Design. The stimuli consisted of 96 prime-target pairs and 12 additional pairs using a \# sign as the prime, which were identical to those of Perfetti and Tan's (1998) Experiment 2.

The prime-target pairs varied along two within-subjects factors: semantic vagueness and prime type. The combination of two levels of semantic vagueness (precise and vague primes) and four levels of prime type (graphically similar, homophonic, semantically similar, and unrelated) yielded eight conditions. Since a between-items design was adopted, there were actually 12 prime-target pairs in each of the eight conditions. The stimuli in each condition of prime type were constructed with high similarity in the intended dimension and relatively low similarity in other dimensions. SOA was varied as 
a between-subjects factor, with levels of 43, 57, and 85 msec. The concept of semantic vagueness was defined, according to Perfetti and Tan (1998), as "a measure of semantic uncertainty of singlecharacter words in isolation" (p. 104).

Procedure. The procedure was the same as that used in Experiment 2 of Perfetti and Tan (1998). The subjects were randomly divided into three groups, with 20 subjects in each, and were run individually.

On each trial a fixation cross was presented at the center of the display monitor for $1 \mathrm{sec}$, followed immediately by a prime character. After the prime was displayed for 43,57 , or $85 \mathrm{msec}$, a target character replaced the prime in the same location on the screen, and the subjects were given up to $2 \mathrm{sec}$ to name the target. The target character remained in view until the subject responded or until $2 \mathrm{sec}$ had elapsed. Naming latencies were measured from the onset of each target with millisecond accuracy by means of a voice key interfaced to the computer.

Each subject received all of the 108 experimental trials, which were presented in random order on the display screen. Twelve practice trials preceded the experimental trials of each subject.

\section{Results and Discussions}

Mean naming latencies for correct responses were calculated for each condition for each subject $\left(F_{1}\right)$ and item $\left(F_{2}\right)$ and entered into separate analyses of variance (ANOVAs). The naming latencies were analyzed both with and without trimming. However, setting cutoffs at 200 and 1,200 msec, as was done by Perfetti and Tan (1998), produced basically the same pattern of results. Thus, for simplicity, only the data without arbitrary trimming are reported in the following sections. Post hoc comparisons were conducted using the protected $t$ test procedure (Fisher's least significant difference). All reported $F$ values are significant at $p=.05$ level, unless otherwise noted. The average naming latencies and error rates are shown in Table 1.

Since there were three groups of subjects in the experiment, we first tested whether or not there were significant differences among the three groups in their responses in either the unrelated prime conditions or the \# prime conditions. Note that although the three groups were under different SOA treatments, the unrelated or \# primes did not relate to the targets in any meaningful way. Thus, any differences among the three groups in these specific conditions should not be considered as SOA effects, but as group effects. There were no reliable differences among the three groups in their performance in the unrelated conditions in either error rates or naming latencies $(F \mathrm{~s}<1)$. Likewise, no reliable differences were found among the three groups in their performance in the \# prime conditions in naming latencies $(F<1)$ or in error rates $[F(2,57)=1.16]$. Thus, the three groups of subjects were reasonably compatible.

Overall, there was clear facilitation for semantic primes on naming latencies, and there was inhibition for graphic primes. Homophonic primes, however, only seemed to affect target naming weakly. Statistical analyses of the naming latencies confirmed these observations. Since (1) using either the unrelated prime conditions or the \# prime conditions as the baseline produced the same pattern of results and (2) Perfetti and Tan (1998) reported their results relative to the unrelated conditions, the statistics reported in the following sections are based on the analyses with the unrelated primes.

The interaction between prime type and SOA was significant relative to the unrelated primes $\left[F_{1}(6,171)=4.18\right.$; $\left.F_{2}(6,176)=4.38\right]$. These results indicate that graphic primes produced a reliable inhibition at all SOA levels $[M \mathrm{~s}=14.5,34$, and $50 \mathrm{msec}$, respectively; protected $t_{1} \mathrm{~s}(171)>2.15$; protected $\left.t_{2} \mathrm{~s}(176)>3.41\right]$. More importantly, a significant and stable facilitation was found for semantic primes at all SOA levels $[M \mathrm{~s}=28,33.5$, and $33 \mathrm{msec}$, respectively; protected $t_{1} \mathrm{~s}(171)>4.16$; protected $\left.t_{2} \mathrm{~s}(176)>4.56\right]$, whereas the homophonic primes significantly affected target naming only at a $57-\mathrm{msec}$ SOA [by $18 \mathrm{msec} ;$ protected $t_{1}(171)=2.75 ;$ protected $t_{2}(176)=$ 3.01].

Furthermore, the meaning precision effect and the precision $\times$ prime type interaction were reliable only by subjects [meaning precision, $F_{1}(1,57)=4.72$; precision $\times$ prime type, $\left.F_{1}(3,171)=12.22\right]$. These results indicate that

Table 1

Average Naming Latencies (in Milliseconds) and Error Rates for Targets as a Function of Prime Type, Prime Semantic Vagueness, and Stimulus Onset Asynchrony (SOA) in Experiment 1 (Beijing Subjects)

\begin{tabular}{|c|c|c|c|c|c|c|c|c|c|c|c|c|}
\hline \multirow[b]{4}{*}{ Condition } & \multicolumn{12}{|c|}{ SOA } \\
\hline & \multicolumn{4}{|c|}{43} & \multicolumn{4}{|c|}{57} & \multicolumn{4}{|c|}{85} \\
\hline & \multicolumn{2}{|c|}{$\begin{array}{l}\text { Naming } \\
\text { Latency }\end{array}$} & \multicolumn{2}{|c|}{$\begin{array}{l}\text { Error } \\
\text { Rate }\end{array}$} & \multicolumn{2}{|c|}{$\begin{array}{l}\text { Naming } \\
\text { Latency }\end{array}$} & \multicolumn{2}{|c|}{$\begin{array}{l}\text { Error } \\
\text { Rate }\end{array}$} & \multicolumn{2}{|c|}{$\begin{array}{l}\text { Naming } \\
\text { Latency }\end{array}$} & \multicolumn{2}{|c|}{$\begin{array}{l}\text { Error } \\
\text { Rate }\end{array}$} \\
\hline & $M$ & $S D$ & $M$ & $S D$ & $M$ & $S D$ & $M$ & $S D$ & $M$ & $S D$ & $M$ & $S D$ \\
\hline \multicolumn{13}{|l|}{ Vague primes } \\
\hline Graphic & 596 & 64 & 2.1 & 3.7 & 613 & 62 & 5.0 & 6.2 & 614 & 34 & 2.5 & 3.9 \\
\hline Homophonic & 568 & 65 & 2.1 & 3.7 & 571 & 45 & 1.2 & 3.1 & 569 & 47 & 0.0 & 0.0 \\
\hline Semantic & 559 & 54 & 0.4 & 1.8 & 565 & 50 & 0.4 & 1.8 & 563 & 49 & 0.8 & 2.6 \\
\hline Unrelated & 581 & 56 & 0.4 & 1.8 & 598 & 48 & 0.4 & 1.8 & 591 & 57 & 0.4 & 1.8 \\
\hline \multicolumn{13}{|l|}{ Precise primes } \\
\hline Graphic & 595 & 69 & 12.9 & 9.9 & 645 & 61 & 11.2 & 9.4 & 662 & 62 & 7.1 & 6.7 \\
\hline Homophonic & 575 & 60 & 0.8 & 2.6 & 582 & 55 & 1.7 & 3.4 & 584 & 50 & 0.4 & 1.8 \\
\hline Semantic & 547 & 60 & 1.2 & 3.1 & 558 & 47 & 0.0 & 0.0 & 547 & 43 & 0.0 & 0.0 \\
\hline Unrelated & 581 & 70 & 1.7 & 3.4 & 592 & 54 & 1.2 & 3.1 & 585 & 48 & 1.7 & 3.4 \\
\hline No. primes & 579 & 73 & 5.4 & 7.3 & 582 & 56 & 2.9 & 4.1 & 575 & 41 & 1.2 & 3.0 \\
\hline
\end{tabular}


both the graphic and the homophonic primes with precise meanings produced longer target-naming latencies than did those with vague meanings [both protected $t_{1} \mathrm{~s}(171)>$ 2.26], but a reversed, nonsignificant trend was found for the semantic primes [protected $t_{1}(171)=1.85, p>.05$ ] Also, meaning precision did not affect target naming in the control conditions (protected $t_{1}<1$ ).

The analyses of errors showed that the main effect of prime type was significant both by subjects and by items $\left[F_{1}(3,171)=59.46 ; F_{2}(3,88)=7.13\right]$. This result indicates that the graphic primes produced more errors $(5.3 \%)$, relative to the homophonic primes, the semantic primes, and the unrelated primes $[M \mathrm{~s}=0.8 \%, 0.4 \%$, and $0.6 \%$, respectively; protected $t_{1} \mathrm{~s}(171)>10.51$; protected $t_{2} \mathrm{~s}(88)>$ 3.63]. Most of the errors in the graphic prime condition were made because the subjects named either the prime or a character graphically similar to the target, rather than the target itself. In addition, the meaning precision $\times$ prime type interaction was significant by subjects $\left[F_{1}(3,171)=\right.$ 22.67], but it was only marginally significant by items $\left[F_{2}(3,88)=2.46, p<.07\right]$. It appears that the graphic primes with precise meaning produced more errors than did the graphic primes with vague meanings $[M \mathrm{~s}=10.4 \%$ and $3.2 \%$; protected $t_{1}(171)=7.51$ ], but meaning precision did not affect other types of primes in error rates [protected $\left.t_{1} \mathrm{~s}(171)<1.16\right]$.

Overall, although there are differences between the error data of Perfetti and Tan (1998) and those of the present experiment (e.g., a reliable SOA effect and an advantage for semantics over phonology were found in their study, but not in the present one), there are also compatible findings in the two experiments (e.g., graphic primes produced more errors than did other types of prime). Since (1) generally very few errors were made in the present experiment and (2) the conclusions of Perfetti and Tan were purely based on their naming latency results, our discussion will be focused mainly on the naming latencies.

When comparing the naming latency results obtained in the two experiments, one can see similar findings (e.g., the existence of both semantic and homophonic facilitation and graphic inhibition) and notable differences. Specifically, Perfetti and Tan (1998) reported that (1) graphic priming shifted from facilitation at a $43 \mathrm{msec}$ SOA to inhibition at longer SOAs, (2) homophonic primes facilitated target naming at 57-msec and other longer SOAs, (3) semantic primes with precise meanings produced facilitatory effects from an 85-msec SOA, whereas those with vague meanings revealed facilitation only at a $115-\mathrm{msec}$ SOA, and (4) all the priming effects were at least $50 \mathrm{msec}$ in magnitude, and many were close to or even larger than $100 \mathrm{msec}$. In contrast, the present experiment demonstrated that (1) only graphic inhibition, but not graphic facilitation, was found across different SOAs, (2) semantic activation appeared very early and was not reliably affected by meaning precision of the primes, (3) no reliable homophonic priming was found at $43-$ and $85-\mathrm{msec}$ SOAs, and a significant effect appeared only at $57 \mathrm{msec}$, and (4) all the priming effects were either equal to or less than $50 \mathrm{msec}$ in magnitude. Most crucially, the demon- stration of strong and early semantic priming, but weak and late homophonic priming, in the present experiment stands in strong contrast to the opposite finding of Perfetti and Tan.

The differences in naming latencies between the present results and those reported by Perfetti and Tan (1998) are striking and are difficult to explain, especially because the two experiments adopted the same kind of subjects (i.e., native Mandarin speakers), design, procedure, and stimuli. Fortunately, another attempt at replication was done simultaneously in Hong Kong, and the results obtained were generally in line with those found in Experiment 1 . We will now consider the Hong Kong study.

\section{EXPERIMENT 2 The Hong Kong Study}

\section{Method}

Subjects. Sixty native Cantonese-speaking undergraduates participated in this experiment for research credit in an introductory psychology course at the Chinese University of Hong Kong. All reported normal or corrected-to-normal vision.

Materials, Design, and Procedure. The stimuli, design, and procedure were the same as those in Experiment 1, except that, all the stimuli shown were in the traditional, complex characters in use in Hong Kong.

Apparatus. The experiment was controlled by a PC-compatible Pentium computer using the DMASTR software. All the stimuli were presented on an EIZO Flex Scan T562-T color monitor. The stimuli were presented in the center of the screen in white 24-point Ming-Ti font against a dark background. The luminance of the display screen was fixed at the same comfortable level for all the subjects (e.g., the luminance of the character 顛 was $10.2 \mathrm{~cd} / \mathrm{m}^{2}$ ). Other aspects of the apparatus were the same as those in Experiment 1.

\section{Results and Discussion}

The data were calculated and analyzed exactly the same way as in Experiment 1, except that in one set of analyses, some items in the homophonic conditions had to be excluded. This is because in Cantonese, 13 prime-target pairs in the homophonic condition are no longer homophones, although all of them, except 1 , are still phonologically similar in the sense that the prime and the target in each of these pairs share at least a certain part of their pronunciations. However, including or excluding those nonhomophonic pairs from the analyses produced basically the same result. Thus, in order to be compatible with Experiment 1, only the data from the analyses including homophonic stimuli are reported in the following sections. Again, all reported $F$ values are significant at $p=.05$ level, unless otherwise noted, and post hoc comparisons were conducted using Fisher's protected $t$ test procedure.

The three groups of subjects were highly comparable, as is reflected by the fact that there were no reliable differences among the three groups in the unrelated prime conditions in either naming latencies or in error rates $(F \mathrm{~S}<1)$. Similarly, no significant differences were found among the three groups in their performance in the \# prime conditions in naming latencies or in error rates $\left(F_{\mathrm{s}}<1\right)$. The mean naming latencies and error rates in 
various conditions are shown in Table 2. Also, since using either the unrelated prime condition or the \# prime condition produced the same pattern of results, as in Experiment 1 , the results reported in the following sections are based on the analyses with unrelated primes as the baseline.

Overall, there was a facilitatory trend for semantic primes on naming latencies, and there was evidence of inhibition for graphic primes. Homophonic primes, however, showed, at most, very weak effects on target naming. Statistical analyses of the naming latencies confirmed these observations. As in Experiment 1, the interaction between prime type and SOA was significant $\left[F_{1}(6,171)=3.62\right.$; $\left.F_{2}(6,150)=5.54\right]$. This result indicates that although no reliable priming effect was observed at $43-\mathrm{msec}$ SOA, semantic primes produced significant facilitation (of about 29 and $26 \mathrm{msec}$, respectively) to target naming at both 57 and $85 \mathrm{msec}$ [both protected $t_{1} \mathrm{~s}(171)>4.67$; both protected $\left.t_{2} \mathrm{~s}(150)>3.75\right]$. For graphic primes, a reliable inhibition ( $34 \mathrm{msec}$ ) was found in the $85-\mathrm{msec}$ SOA condition [protected $t_{1}(171)=6.24$; protected $t_{2}(150)=5.00$ ] However, no reliable priming effect was found for homophonic primes at any SOAs [protected $t_{1} \mathrm{~s}(171)<1.82$, $p \mathrm{~s}>.05$; protected $\left.t_{2} \mathrm{~s}(150)<1.47, p \mathrm{~s}>.10\right]$.

Furthermore, the following effects were reliable by subjects, but they failed to approach significance by items: meaning precision $\left[F_{1}(1,57)=4.50\right]$, prime type $\left[F_{1}(3,171)=22.52\right]$, and meaning precision $\times$ prime type $\left[F_{1}(3,171)=3.02\right]$. These results indicate that the graphic primes with precise meanings produced longer naming latencies, relative to those with vague meanings [protected $t_{1}(171)=3.49$ ], but meaning precision did not affect target naming in the other conditions [all protected $\left.t_{1} \mathrm{~s}(171)<1.65, p \mathrm{~s}>.10\right]$. Note that these results were less reliable, in the sense that they were only significant in one of the two analyses conducted. Thus, our discussion will be focused mainly on the prime type $\times$ SOA interaction, which was reliable both by subjects and by items.

The analyses of errors revealed a significant effect of prime type $\left[F_{1}(3,171)=38.74 ; F_{2}(3,75)=2.16\right]$, indicating that targets in the graphic prime condition produced more errors $(M=7.0 \%)$, relative to those in both the semantic prime condition and the homophonic prime condition $[M \mathrm{~s}=1.0 \%$ and $1.0 \%$, respectively; both protected $t_{1} \mathrm{~s}(171)>9.37$; both protected $t_{2} \mathrm{~s}(75)>2.66$ ]. However, the difference between the graphic prime condition and the unrelated prime condition $(M=3.5 \%)$ was reliable by subjects [protected $t_{1} \mathrm{~s}(171)=5.47$ ], but not by items [protected $\left.t_{2}(75)=1.95, p>.05\right]$. Again, as in Experiment 1, the errors in the graphic prime condition were made mostly because the subjects named either the prime or a character graphically similar to the target, rather than the target itself. Moreover, the meaning precision effect and the precision $\times$ prime type interaction were significant only by subjects $\left[F_{1}(1,57)=19.02 ; F_{1}(3,171)=20.68\right]$. In general, more errors were made in both the graphic and the control conditions with precise meanings than in the corresponding conditions with vague meanings [both protected $t_{1} \mathrm{~s}(171)>3.18$ ], yet meaning precision did not affect the error rates in the homophonic and semantic conditions [both protected $t_{1} \mathrm{~s}(171)<1.43, p \mathrm{~s}>.10$ ].

The results of the present experiment can easily be summarized as follows: (1) A reliable graphic inhibition appeared only at $85 \mathrm{msec}$, and no graphic facilitation effect was shown at any of the SOAs, (2) there was no reliable homophonic priming in any SOAs, (3) there was early semantic activation (i.e., significant semantic facilitation at both 57- and 85-msec SOAs), but no effect of meaning precision on the pattern of semantic effects, (4) all the priming effects found in the present experiment were either equal to or smaller than $50 \mathrm{msec}$, and (5) graphic primes generally produced more errors than did other primes. Thus, the present experiment replicated the most

Table 2

Average Naming Latencies (in Milliseconds) and Error Rates for Targets as a Function of Prime Type, Prime Semantic Vagueness, and Stimulus Onset Asynchrony (SOA) in Experiment 2 (Hong Kong Subjects)

\begin{tabular}{|c|c|c|c|c|c|c|c|c|c|c|c|c|}
\hline \multirow[b]{4}{*}{ Condition } & \multicolumn{12}{|c|}{ SOA } \\
\hline & \multicolumn{4}{|c|}{43} & \multicolumn{4}{|c|}{57} & \multicolumn{4}{|c|}{85} \\
\hline & \multicolumn{2}{|c|}{$\begin{array}{l}\text { Naming } \\
\text { Latency }\end{array}$} & \multicolumn{2}{|c|}{$\begin{array}{l}\text { Error } \\
\text { Rate }\end{array}$} & \multicolumn{2}{|c|}{$\begin{array}{l}\text { Naming } \\
\text { Latency }\end{array}$} & \multicolumn{2}{|c|}{$\begin{array}{l}\text { Error } \\
\text { Rate }\end{array}$} & \multicolumn{2}{|c|}{$\begin{array}{l}\text { Naming } \\
\text { Latency }\end{array}$} & \multicolumn{2}{|c|}{$\begin{array}{l}\text { Error } \\
\text { Rate }\end{array}$} \\
\hline & $M$ & $S D$ & $M$ & $S D$ & $M$ & $S D$ & $M$ & $S D$ & $M$ & $S D$ & $M$ & $S D$ \\
\hline \multicolumn{13}{|l|}{ Vague primes } \\
\hline Graphic & 673 & 52 & 4.2 & 6.9 & 674 & 64 & 1.7 & 3.4 & 691 & 52 & 3.7 & 5.0 \\
\hline Homophonic & 659 & 64 & 2.5 & 5.1 & 667 & 73 & 0.6 & 2.8 & 664 & 65 & 1.2 & 5.6 \\
\hline Semantic & 658 & 56 & 2.1 & 3.7 & 659 & 66 & 1.7 & 4.3 & 647 & 47 & 1.2 & 4.1 \\
\hline Unrelated & 667 & 55 & 1.7 & 3.4 & 675 & 55 & 1.2 & 3.1 & 670 & 41 & 3.3 & 4.2 \\
\hline \multicolumn{13}{|l|}{ Precise primes } \\
\hline Graphic & 689 & 70 & 10.0 & 7.9 & 682 & 76 & 9.2 & 8.9 & 724 & 63 & 13.3 & 9.5 \\
\hline Homophonic & 676 & 75 & 1.7 & 7.4 & 670 & 71 & 0.0 & 0.0 & 670 & 49 & 0.0 & 0.0 \\
\hline Semantic & 663 & 59 & 0.8 & 2.6 & 640 & 57 & 0.0 & 0.0 & 648 & 55 & 0.4 & 1.8 \\
\hline Unrelated & 667 & 61 & 5.4 & 4.9 & 682 & 59 & 4.6 & 5.0 & 676 & 52 & 5.0 & 5.7 \\
\hline No. primes & 668 & 64 & 2.9 & 4.9 & 672 & 52 & 1.7 & 3.4 & 670 & 61 & 1.7 & 3.4 \\
\hline
\end{tabular}


crucial finding of Experiment 1, namely, strong and early semantic priming, relative to homophonic priming.

\section{GENERAL DISCUSSION}

The present experiments were conducted in an attempt to replicate the results of Experiment 2 reported by Perfetti and Tan (1998). The results of the two experiments conducted in two different laboratories with native speakers of two different Chinese dialects in the present study indicate that the design and the stimuli used in Perfetti and Tan can indeed produce a reasonably stable pattern of findings. In fact, there are certain findings that were found in all three experiments. These include, for instance, relatively high error rates in the graphic prime conditions, as well as inhibitory effects from graphically similar primes and facilitatory effects from semantically similar primes in target naming. However, it was also discovered that the consistent and reliable pattern of findings demonstrated across the present experiments differed in important respects from those reported in the original experiment of Perfetti and Tan. To illustrate the differences in findings between the two studies, Figure 1 shows the $\mathrm{SOA} \times$ prime type interaction obtained in all three experiments.

As can be seen in Figure 1, the most notable differences between the two sets of experiments in naming latencies are (1) the relative importance of semantic and phonological activation and the onsets of corresponding effects (they found early and strong phonological priming, but weak and late semantic effects, whereas we discovered the completely opposite pattern), (2) the pattern of graphical priming (whereas they reported that graphic priming shifted from facilitation at the shortest SOA to inhibition at longer SOAs, we found only graphic inhibition), and (3) the overall magnitude of priming (the size of their effects being two or three times greater than ours). In addition to these differences between the previous and the present experiments, there is another finding that is not in line across the different experiments. Specifically, one of the major findings of Perfetti and Tan (1998) is that the precision of meaning of the primes was the main determinant of the pattern of semantic priming, yet this factor did not affect the pattern of semantic priming in the present experiments (see Figure 2 for semantic-priming effects as a function of meaning precision in the different experiments). ${ }^{3}$ Finally, in the error data, they found clear differences between semantic and phonological primes and a reliable effect of SOA, but these effects were not found in the present study. Since the error rates found in all three experiments are generally low and are not as revealing as the naming latency results in character recognition, our discussion in the following sections will focus mainly on the latency results and, especially, on the target issuenamely, the relative time course of semantic and phonological activation in recognizing Chinese characters.

Note that because Experiment 1 adopted the same kind of subjects and the identical form of simplified characters as those in their original study, we know that these two factors (type of subjects and form of script) are not responsible for the discrepancy between the present results and those of Perfetti and Tan (1998). We also know that differ-
Perfetti \& Tan

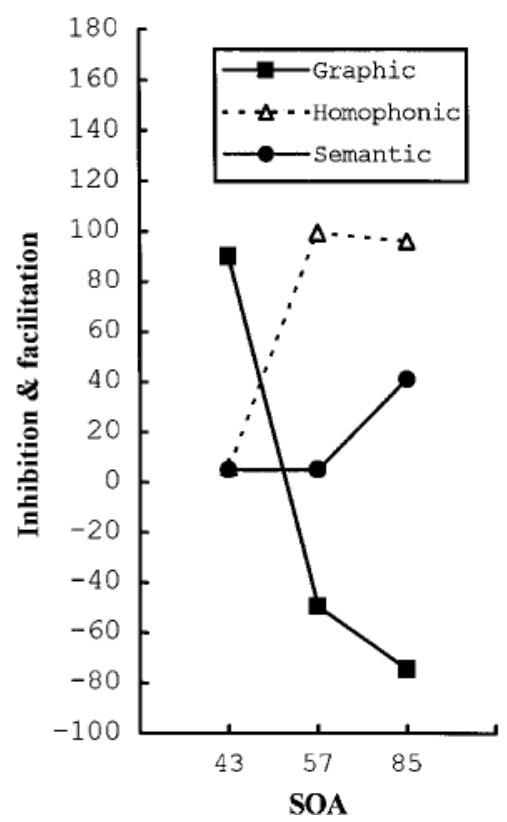

Beijing Data

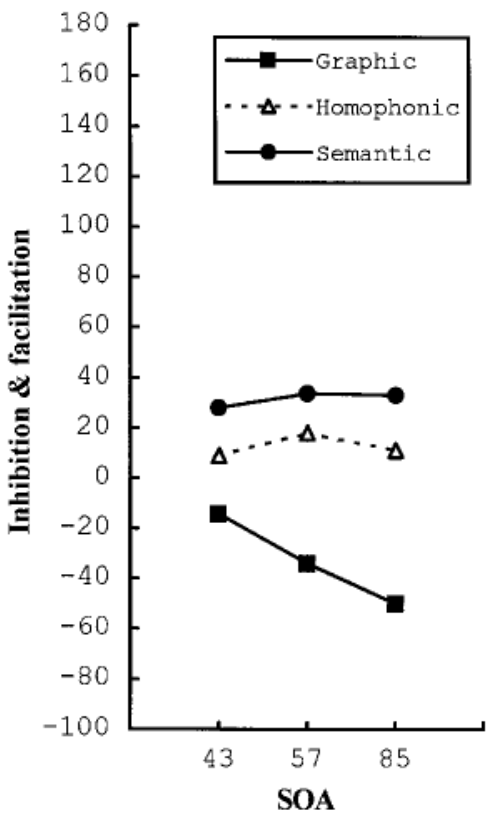

Hong Kong Data

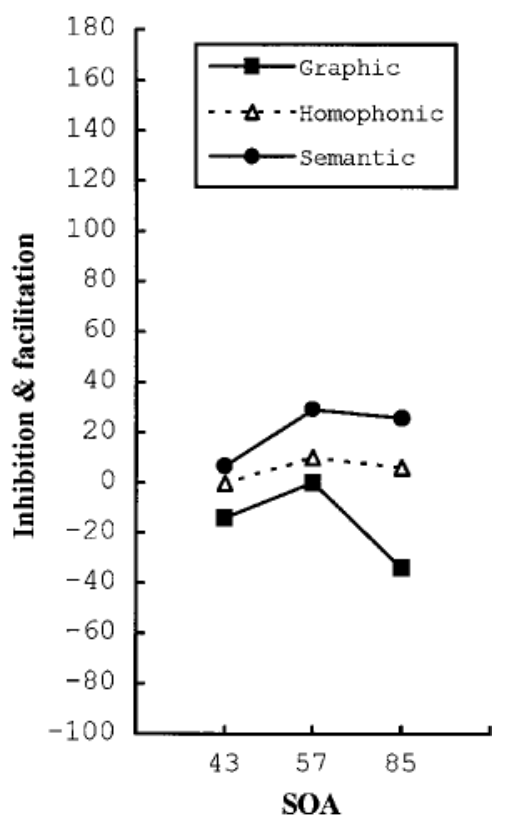

Figure 1. Mean inhibition and facilitation (i.e., the differences between mean target naming latencies in the unrelated control condition and those in the other prime type conditions) as a function of prime type and stimulus onset asynchrony (SOA) in Experiment 2 of Perfetti and Tan (1998) and in Experiments 1 and 2 of the present study. 

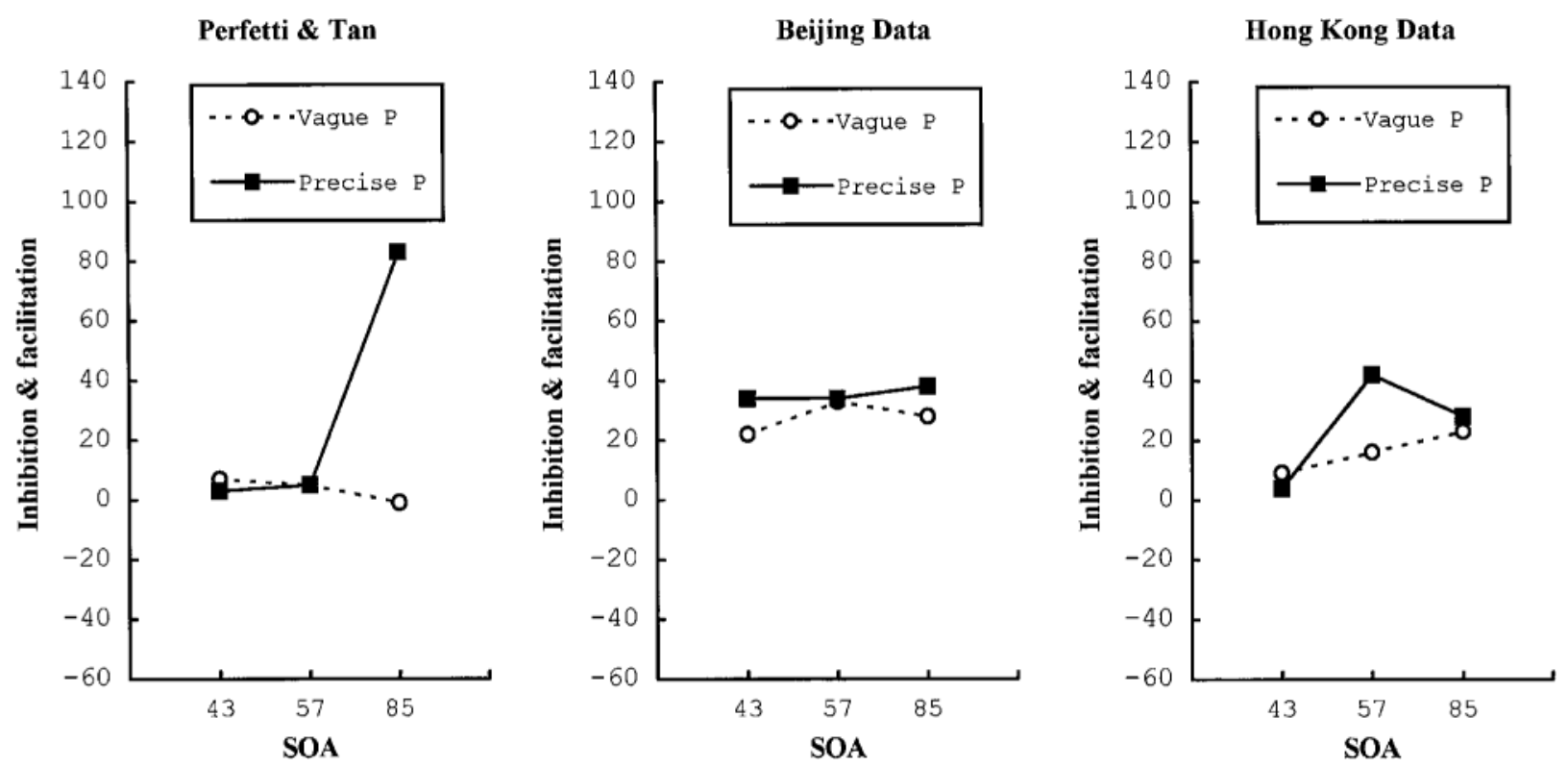

Figure 2. Mean inhibition and facilitation (i.e., the differences between mean target naming latencies in the unrelated control condition and those in the semantically similar prime condition) as a function of meaning precision and stimulus onset asynchrony (SOA) in Experiment 2 of Perfetti and Tan (1998) and in Experiments 1 and 2 of the present study.

ences in design, procedure, and stimuli cannot be used to account for the different findings in the two studies, because these aspects were identical across experiments.

It is important to note that, although the discrepancy between the Perfetti and Tan (1998) study and the present set of experiments could be due to reasons that we are not in a position to know, the general pattern of the present results was replicated in two different laboratories. Moreover, unlike Perfetti and Tan's study, the magnitude of the priming effects in the present experiments are much more compatible with those obtained in other related studies (e.g., Forster \& Davis, 1991; Lukatela \& Turvey, 1994; Perea \& Gotor, 1997; Zhou \& Marslen-Wilson, 1997). Thus, the consistent and reliable results of our experiments raise serious questions about the replicability of Perfetti and Tan's findings. Following the same rationale, we believe that our results are more revealing about lexical activation during the recognition of Chinese characters than are those of the other study. In fact, the demonstration of earlier and stronger semantic priming than phonological priming in the present experiments clearly suggests that semantic, rather than phonological, activation plays a crucial role in the recognition of Chinese characters.

Moreover, even if the design and the stimuli of Perfetti and Tan (1998) are capable of generating reliable results, the interpretation of the obtained results should be made cautiously. This is because the degree of similarity between different primes and their corresponding targets along various lexical dimensions simply were not equated in their study. Specifically, whereas the phonological similarity between primes and targets was set at the most extreme level (i.e., homophonic), the semantic and graphic similarities, being only similar and not identical, were clearly not at a comparable level. Thus, any difference in the pattern of results found in different conditions could have been due to different patterns of activation, different levels of prime-target similarity, or the interaction of the two factors. However, this problem cannot be solved by using homographs, since these are effectively repetition items. Instead, one should assess phonological priming by using phonological neighbors as primes and targets, rather than homophones. Confounding between the degree of stimulus similarity and lexical dimension has been overlooked in many related studies (e.g., Perfetti \& Tan, 1998; Perfetti \& Zhang, 1991, 1995; Tan et al., 1996). Obviously, this confounding and its possible impact on visual word recognition should be carefully examined empirically. Before this is done, differential degrees of stimulus similarity in various experimental conditions should at least be taken into account in interpreting the corresponding results on lexical activation in visual word recognition.

In conclusion, the study by Perfetti and Tan (1998) on lexical activation in Chinese character identification and the conclusion from that study concerning the time course of graphic, phonological, and semantic activation during the recognition of Chinese characters are called into question. Contrary to their claims, we found no evidence that phonological activation plays a critical role in Chinese character recognition and/or processing (for a similar finding, see, e.g., Chen et al., 1995; Chen \& Juola, 1982; Shen \& Forster, 1999; Wong \& Chen, 1999). Rather, we found clear and consistent evidence across both experiments in the present study that it is semantic rather than phonological activation, which is robust and appears very quickly and early in the course of lexical access in Chinese character recognition, that is critical. 
Obviously, these results are inconsistent with the idea that phonology is compulsory in the recognition of characters or words, independent of the writing system. Our finding of earlier and stronger access to semantic than to phonological information is particularly remarkable in light of the following two considerations: (1) Unlike those semantic tasks, such as categorization, the naming task adopted in the present study is actually biased toward the use of phonological rather than semantic information, and (2) the degree of phonological similarity between primes and targets is much higher than the degree of semantic similarity. Finally, the typical method of carrying out a priming experiment involves a within-items design (i.e., the same target pairs with two or more different primes). The present experiments, following the experiment of Perfetti and Tan, adopted a between-items design. With different targets in different prime conditions, it is possible that some potential confounds might not have been avoided. Thus, in this respect, it would seem worth while to reexamine the related issues with a within-items design. Nevertheless, the experiments described here attest to the central importance of replication in the scientific study of Chinese reading and related processes, especially because (1) the research in this exciting area has only just begun and (2) there are many differences (in tasks, materials, participants, etc.) between studies on related issues.

\section{REFERENCES}

Chen, H.-C. (1992). Reading comprehension in Chinese. In H.-C. Chen \& O. J. L. Tzeng (Eds.), Language processing in Chinese (pp. 175205). Amsterdam: Elsevier.

Chen, H.-C. (1996). Chinese reading and comprehension: A cognitive psychology perspective. In M. H. Bond (Ed.), Handbook of Chinese psychology (pp. 43-62). Hong Kong: Oxford University Press.

Chen, H.-C., Flores d'Arcais, G. B., \& Cheung, S. L. (1994, December). Is phonological activation automatic in character recognition in Chinese? Paper presented at the Asian-Australian Workshop on Cognitive Processing of Asian Languages, Sydney.

Chen, H.-C., Flores d’ Arcais, G. B., \& Cheung, S. L. (1995). Orthographic and phonological activation in recognizing Chinese characters. Psychological Research, 58, 144-153.

Chen, H.-C., \& Juola, J. F. (1982). Dimensions of lexical coding in Chinese and English. Memory \& Cognition, 10, 216-224.

Forster, K. I., \& DAVIS, C. (1991). The density constraint on formpriming in the naming task: Interference effects from a masked prime. Journal of Memory \& Language, 30, 1-25.

Lukatela, G., \& Turvey, M. T. (1994). Visual lexical access is initially phonological: 1 . Evidence from associative priming by words, homophones, and pseudohomophones. Journal of Experimental Psychology: General, 123, 107-128.

Perea, M., \& Gotor, A. (1997). Associative and semantic priming effects occur at very short stimulus-onset asynchronies in lexical decision and naming. Cognition, 62, 223-240.

Perfetti, C. A., \& TAn, L. H. (1998). The time course of graphic, phonological, and semantic activation in Chinese character identification. Journal of Experimental Psychology: Learning, Memory, \& Cognition, 24, 101-118.
Perfetti, C. A., \& Zhang, S. (1991). Phonological processes in reading Chinese characters. Journal of Experimental Psychology: Learning, Memory, \& Cognition, 17, 633-643.

Perfetti, C. A., \& Zhang, S. (1995). Very early phonological activation in Chinese reading. Journal of Experimental Psychology: Learning, Memory, \& Cognition, 21, 24-33.

Shen, D., \& Forster, K. I. (1999). Masked phonological priming in reading Chinese words depends on the task. Language \& Cognitive Processes, 14, 429-459.

Tan, L. H., Hoosain, R. \& Siok, W. W. T. (1996). Activation of phonological codes before access to character meaning in written Chinese. Journal of Experimental Psychology: Learning, Memory, \& Cognition, 22, 865-882.

Tan, L. H., \& Perfetti, C. A. (1997). Visual Chinese character recognition: Does phonological information mediate access to meaning? Journal of Memory \& Language, 37, 41-57.

Wong, E. K. F., \& CHEN, H.-C. (1999). Orthographic and phonological processing in reading Chinese text: Evidence from eye fixations. Language \& Cognitive Processes, 14, 461-480.

Zhou, X., \& MARSLEN-Wilson, W. (1997). Sublexical processing in reading Chinese. In M. G. Shafto \& P. Langley (Eds.) Proceedings of the Nineteenth Annual Conference of the Cognitive Science Society (pp. 832-837). Mahwah, NJ: Erlbaum.

Zhou, X., \& MARslen-Wilson, W. (1999). Phonology, orthography, and lexical semantic activation in reading Chinese. Journal of Memory \& Language, 41, 579-606.

\section{NOTES}

1. Chinese characters are typically monosyllabic. Since there are far fewer possible syllables (about 400 in Mandarin, excluding tones, or about 1,300 with tones) than there are characters that are regularly used (about 4,600), the degree of homophony in the language is fairly high.

2. A large number of Chinese characters (over $80 \%$ ) consist of complex characters formed of two components, one of which (i.e., the signific or radical) provides a graphically distinctive, categorical cue to the meaning of the character; the other component (i.e., the phonetic) may cue in an all-or-none fashion the pronunciation of the character as a whole. However, the phonetic parts in these complex characters are basically themselves characters having their own pronunciation (thus providing phonetic cues) and different meanings (their meanings being typically different from the meanings of the complex characters in which they are embedded). Furthermore, these phonetic components (roughly about 800 in total) do not always provide constant and reliable cues to the pronunciation. Some may serve as phonetics in some complex characters, but as radicals in others.

3. The lack of a robust meaning precision effect is puzzling. This may be due to the fact that the meaning of a Chinese character is highly context dependent (Chen, 1992, 1996). In fact, although many individual characters can be independently used as words in text, they can almost always be used with other characters to form multicharacter words with distinctively different meanings. Thus, it is possible that a meaning precision effect is likely to be found at a multicharacter word level, rather than at a character level. Another possible explanation for the lack of a meaning precision effect, at least in the semantic priming situation, is that the priming is retrospective. Specifically, when a candidate entry for the target is located, an attempt is made to link it semantically with the prior context, and if such a link can be established, faster performance results. In such a system, the meaning precision of the prime might not matter at all. These possibilities need to be examined in future research.

(Manuscript received March 21, 2000; revision accepted for publication December 19, 2000.) 